using AUC of the DAS28 was $0.607(95 \% \mathrm{Cl} 0.503$ to $0.711, \mathrm{p}=0.043)$ with an optimal cut-off $2.5 \mu \mathrm{g} / \mathrm{mL}$.

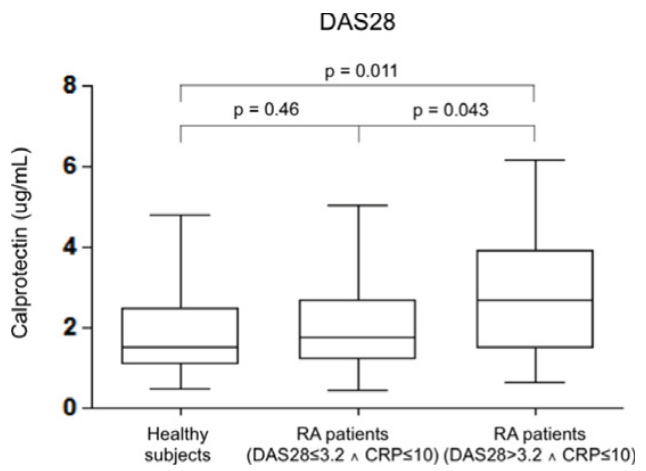

Conclusions: The present study demonstrates that calprotectin may reflect inflammatory activity in RA patients where CRP fails to do so.

References:

[1] Pincus T, Sokka T. Laboratory tests to assess patients with rheumatoid arthritis: advantages and limitations. Rheum Dis Clin North Am 2009;35(4):731-4.

[2] Sokka T, Pincus T. Erythrocyte sedimentation rate, C-reactive protein, or rheumatoid factor are normal at presentation in $35 \%>45 \%$ of patients with rheumatoid arthritis seen between 1980 and 2004: analyses from Finland and the United States. J Rheumatol 2009;36(7):1387-90.

[3] Pincus T, Gibson KA, Shmerling RH. An evidence-based approach to laboratory tests in usual care of patients with rheumatoid arthritis. Clin Exp Rheumatol 2014;32(5 Suppl 85):S-23-8.

Acknowledgements: This work was supported by a project of the Ministry of Health of the Czech Republic for conceptual research development by organization [023728], Charles University Grant Agency (GAUK grant), Czech Republic [880217] and Specific Academy Research Projects (SVV) [260 031].

Disclosure of Interest: None declared

DOI: 10.1136/annrheumdis-2017-eular.3340

\section{THU0114 EFFECTS OF SMOKING ON BARICITINIB EFFICACY IN PATIENTS WITH RHEUMATOID ARTHRITIS: POOLED ANALYSIS FROM TWO PHASE 3 CLINICAL TRIALS}

J. Curtis $^{1}$, P. Emery ${ }^{2}$, G. Burmester ${ }^{3}$, V. Arora ${ }^{4}$, J. Alam ${ }^{4}$, D. Muram ${ }^{4}$, L. Klareskog ${ }^{5} .{ }^{1}$ University of Alabama at Birmingham, Birmingham, United States; ${ }^{2}$ Leeds MSK Biomed/Chapel Allerton Hospital, Leeds, United Kingdom; ${ }^{3}$ Universitatsklinikum Charite, Berlin, Germany; ${ }^{4}$ Eli Lilly and Company, Indianapolis, United States; ${ }^{5}$ Karolinska Institutet, Stockholm, Sweden

Background: The efficacy of some rheumatoid arthritis (RA) therapies is reduced among patients who are smokers.

Objectives: This post-hoc analysis of two phase 3 studies assessed the effects of patient smoking status on the response to baricitinib treatment in patients with RA.

Methods: In RA-BEAM (NCT01710358), patients with inadequate response to methotrexate were randomized to placebo once-daily (QD) $(\mathrm{N}=488)$, baricitinib $4 \mathrm{mg}$ QD ( $\mathrm{N}=487)$, or adalimumab $40 \mathrm{mg}$ biweekly $(\mathrm{N}=330) .{ }^{1}$ In RA-BUILD (NCT01721057), patients with inadequate response to conventional synthetic disease modifying antirheumatic drugs (csDMARDs) were randomized to placebo ( $\mathrm{N}=228$ ) or baricitinib (2 mg, $\mathrm{N}=229$; or $4 \mathrm{mg}, \mathrm{N}=227$ ) $\mathrm{QD} .^{2}$ Patients continued background csDMARD therapy in both studies. This post-hoc analysis was conducted in the placebo $(\mathrm{N}=716)$ and baricitinib $4 \mathrm{mg}(\mathrm{N}=714)$ patients. Patientreported smoking status was categorized as current (smokers) or not current (non-smokers).

Results: Among 1,430 evaluable patients who received placebo or baricitinib 4 mg, $290(20.3 \%)$ were smokers. Smoking status at baseline did not affect the clinical results of treatment with baricitinib for 24 weeks; smokers who received

Table 1. Efficacy outcomes at week 24 with data up to rescue

\begin{tabular}{|c|c|c|c|c|}
\hline & \multicolumn{2}{|c|}{ Placebo $(\mathrm{N}=716)$} & \multicolumn{2}{|c|}{ Baricitinib $4 \mathrm{mg}(\mathrm{N}=714)$} \\
\hline & $\begin{array}{l}\text { Smoker } \\
(\mathrm{n}=139)\end{array}$ & $\begin{array}{c}\text { Non-Smoker } \\
(\mathrm{n}=577)\end{array}$ & $\begin{array}{l}\text { Smoker } \\
(n=151)\end{array}$ & $\begin{array}{c}\text { Non-Smoker }) \\
(\mathrm{n}=562)\end{array}$ \\
\hline ACR20 & $44(31.7)$ & $231(40.0)$ & $108(71.5)$ & $399(71.0)$ \\
\hline ACR50 & $24(17.3)$ & $119(20.6)$ & $76(50.3)$ & $270(48.0)$ \\
\hline ACR70 & $8(5.8)$ & $49(8.5)$ & 49 (32.5) & $151(26.9)$ \\
\hline SDAI $\leq 3.3$ & $5(3.6)$ & $19(3.3)$ & $24(15.9)$ & $88(15.7)$ \\
\hline SDAI $\leq 11$ & $24(17.3)$ & $137(23.7)$ & $72(47.7)$ & $294(52.3)$ \\
\hline $\mathrm{CDAl} \leq 2.8$ & $4(2.9)$ & $24(4.2)$ & $24(15.9)$ & $89(15.8)$ \\
\hline $\mathrm{CDAI} \leq 10$ & $22(15.8)$ & $137(23.7)$ & $71(47.0)$ & $289(51.4)$ \\
\hline DAS28-hsCRP $\leq 3.2$ & $24(17.3)$ & $123(21.3)$ & 75 (49.7) & $296(52.7)$ \\
\hline DAS28-hsCRP $<2.6$ & $9(6.5)$ & $53(9.2)$ & $51(33.8)$ & $192(34.2)$ \\
\hline $\mathrm{HAQ}-\mathrm{DI} \geq 0.3$ & 47 (33.8) & $219(38.0)$ & $103(68.2)$ & $346(61.6)$ \\
\hline HAQ-DI $\geq 0.22$ & $61(43.9)$ & $254(44.0)$ & $108(71.5)$ & $381(67.8)$ \\
\hline mTSS change $\leq 0^{*}$ & $68 / 96(70.8)$ & $250 / 356(70.2)$ & $78 / 107$ (72.9) & $304 / 363(83.7)$ \\
\hline
\end{tabular}

Data are $\mathrm{n}(\%) .{ }^{*} \mathrm{mTTS}$ data are from RA-BEAM only. placebo were numerically less likely than non-smokers receiving placebo to achieve most clinical outcomes (Table). Baricitinib's effect on modified total Sharp score was more pronounced among nonsmokers (interaction p-value $=0.07$ ). ACR20/50/70 $=20 \%, 50 \%$, and $70 \%$ improvement in American College of Rheumatology criteria; CDAl=Clinical Disease Activity Index; DAS28-hsCRP=Disease Activity Score 28-high sensitivity C-reactive protein; HAQ-DI=Health Assessment Questionnaire-Disability Index; mTSS=modified total Sharp score; SDAI=Simple Disease Activity Index.

Conclusions: This analysis of smokers and non-smokers in two RA trials demonstrated that the beneficial effect of baricitinib treatment versus placebo was similar on all clinical endpoints, but may differ for structural damage progression. References:

[1] Taylor PC et al. Arthritis Rheumatol 2015;67(suppl 10) abst 2L.

[2] Dougados M et al. Ann Rheum Dis 2017;76:88-95.

Disclosure of Interest: J. Curtis Grant/research support from: AbbVie, Amgen, BMS, Janssen, Pfizer, Roche/Genentech, Corrona, UCB, Myriad, Eli Lilly and Company, Consultant for: AbbVie, Amgen, BMS, Janssen, Pfizer, Roche/Genentech, Corrona, UCB, Myriad, Eli Lilly and Company, Employee of: University of Alabama at Birmingham, P. Emery Consultant for: Pfizer, MSD, Abbvie, BMS, UCB, Roche, Novartis, Samsung, Sandoz, Eli Lilly and Company, G. Burmester Consultant for: Eli Lilly and Company, V. Arora Employee of: Eli Lilly and Company, J. Alam Employee of: Eli Lilly and Company, D. Muram Employee of: Eli Lilly and Company, L. Klareskog Grant/research support from: Janssen, Pfizer, BMS, GSK, AbbVie, Roche.

DOI: 10.1136/annrheumdis-2017-eular.1341

\section{THU0115 DISABILITY (HAQ) AND QUALITY OF LIFE (SF-12) AS RELATED TO ADHERENCE AND HEALTH LITERACY IN PATIENTS WITH RHEUMATOID ARTHRITIS}

J.G. Kuipers $^{1}$, M. Koller ${ }^{2}$, F. Zeman ${ }^{2}$, K. Mueller $^{2}$, J.U. Rueffer ${ }^{3}$.

${ }^{1}$ Rheumatology, Red Cross Hospital Bremen, Bremen; ${ }^{2}$ Center for Clinical Studies, University Hospital Regensburg, Regensburg; ${ }^{3}$ German Fatigue Society, Cologne, Germany

Background: Disabilities in daily living and quality of life are key endpoints to evaluate the outcome of treatment for rheumatoid arthritis (RA). Among factors that may contribute to good outcome are adherence (i.e., the extent to which patients' behaviors corresponds with agreed recommendations from their doctor) and health literacy (patients' understanding and use of health information).

Objectives: The survey included a representative, nationwide sample of German physicians specialized in RA and patients with RA. The physician questionnaire included the disease activity score (DAS28) and medical prescriptions. The patient questionnaire included fatigue (EORTC QLQ-FA13), health assessment questionnaire (HAQ), quality of life (SF-12), health education literacy (HELP), and patients' listings of their medications.

Methods: Adherence was operationalized in various ways: patient-reported (CQR5), behavioral (correspondence between physicians and patients listings of medications), physician-assessed (five-point rating scale ranging from $1=$ very adherent to $5=$ not at all adherent) and a combined measure of physician rating ( $1=$ very adherent, $0=$ less adherent) and the match between physicians' prescriptions and patients' accounts of their medications ( 1 = perfect match, 0 = no perfect match), leading to three categories of adherence: high, medium and low. Linear regressions were calculated using HAQ and SF-12 (physical and psychological) as dependent variables and adherence, health literacy and the set of demographic and clinical variables as predictor variables.

Results: A total of 708 pairs of patient and physician questionnaires were analyzed. The mean age of the patients, of whom $73 \%$ were women, was 60 years $(S D=12)$.

Multiple regression analyses show, that health literacy is an independent predictor for HAQ and both SF-12 scales. Adherence by doctor is an independent predictor for both SF-12 scales while the adherence composite score is an independent predictor for HAQ and SF-12 psychological. Taking all 4 rheumatoid medications as prescribed is an independent predictor for HAQ and SF-12 physical. All models

Table 3: Multiple linear regression models

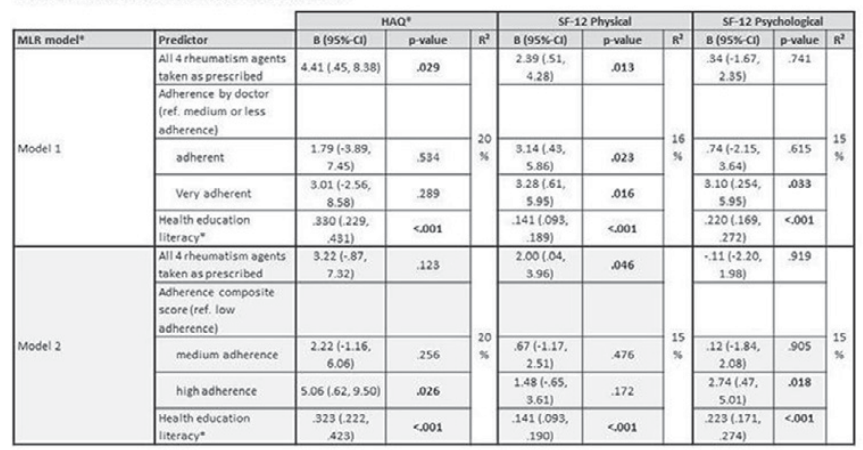

All models are adjusted for sex, age, drinking alcohol (y/n), smoking status (y/n) and sport activties (y/n);
B, regression coefficient; $95 \%-C l, 95 \%$ - confidence interval; "linearly transformed on a scale from 0 (negativelow) to 100 (positive high) 